\title{
Article \\ Shift Strategy Optimization for Automatic Transmission of Heavy Trucks Based on Dynamic Programming Algorithm
}

\author{
Heng Zhang ${ }^{\mathbb{D}}$, Xinxin Zhao* ${ }^{\mathbb{D}}$, Jue Yang $\mathbb{D}$ and Weiwei Yang \\ School of Mechanical Engineering, University of Science and Technology Beijing, Beijing 100083, China; \\ zhanghengustb@hotmail.com (H.Z.); yangjue@ustb.edu.cn (J.Y.); weiweiyang@ustb.edu.cn (W.Y.) \\ * Correspondence: xinxinzhao@ustb.edu.cn; Tel.: +86-010-6233-3221
}

check for updates

Citation: Zhang, H.; Zhao, X.; Yang, J.; Yang, W. Shift Strategy

Optimization for Automatic

Transmission of Heavy Trucks Based on Dynamic Programming Algorithm. Appl. Sci. 2021, 11, 5555. https:// doi.org/10.3390/app11125555

Academic Editor: Jan Awrejcewicz

Received: 29 April 2021

Accepted: 4 June 2021

Published: 16 June 2021

Publisher's Note: MDPI stays neutral with regard to jurisdictional claims in published maps and institutional affiliations.

Copyright: (c) 2021 by the authors. Licensee MDPI, Basel, Switzerland. This article is an open access article distributed under the terms and conditions of the Creative Commons Attribution (CC BY) license (https:// creativecommons.org/licenses/by/ $4.0 /)$.
Abstract: The shift strategy of automatic transmission plays a vital role in the smoothness and economy of heavy-duty mining trucks. In this paper, an engine fuel consumption model, a $6+2$ speed automatic transmission model, and a vehicle resistance model are built in MATLAB. Combined with the development of smart mining technology, the traditional two-parameter economic shift strategy is corrected based on vehicle load and road slope. The dynamic programming optimization algorithm is used to extract the best economical shift strategy under known working conditions to reduce the fuel consumption and the number of shifts. Finally, simulation experiments of the optimized shift strategy by dynamic programming in a typical mine work cycle are carried out. The simulation results show that the engine speed and output torque are maintained in a relatively stable and efficient working range by using the proposed shift strategy. Compared with the traditional two-parameter shift strategy, dynamic programming has advantages in reducing fuel consumption and shift numbers.

Keywords: automatic transmission; shift strategy; dynamic programming; fuel consumption; shift smoothness

\section{Introduction}

Different from passenger cars, heavy-duty mining trucks have to face problems such as poor driving conditions, huge load capacity, and high fuel consumption [1,2]. The highpower hydraulic automatic transmission (AT) uses clutches (or brakes) to shift gears, which can ensure shifting without interruption of power and achieve good shifting smoothness; the torque converter (TC) enables greater torque transmission at low speeds; and the application of planetary row structure is reliable when shifting frequently. These three features, which other types of transmissions do not have, make AT widely used in the heavy truck field [3-5].

According to statistics, fuel consumption costs account for more than $30 \%$ of all maintenance costs during the entire working cycle of heavy-duty mining trucks $[6,7]$. To achieve energy saving and emission reduction, while meeting the power requirements of vehicles, formulating the best economical shift strategy is a current research focus in the field of automatic transmission [8,9]. Some researchers improve the traditional twoparameter (vehicle speed and throttle opening) shifting rules by adding more reference parameters, such as vehicle acceleration [10], mass [11,12], road slope [11], and the driver intention $[13,14]$. In order to improve fuel economy and electric bus dynamic performance, Li et al. [10] proposed the concept of equivalent slope and used a three-parameter shift schedule based on vehicle acceleration. Through real-time identification of road conditions, Lei and Liu [11] proposed a generalized load theory under different road grades and vehicle masses, and then deduced a three-parameter shift strategy based on generalized load. Zhang et al. [14] analyzed and summarized the characteristics of driver intentions under different driving environments, using the driver's intention as the third parameter to optimize the shift schedule. However, these shift strategies with increasing types 
of parameters often do not have the ability to predict the future driving environment. They only achieve the best instantaneous best fuel economy, but not the global optimal shift strategy. Moreover, these traditional economic shift schedules often sacrifice other performance (such as frequent shifting).

Because of this, some scholars used predictive control to optimize the shift strategies $[15,16]$. Ngo et al. [17] comprehensively considered the power distribution strategy, engine start-stop, and gear control problems of hybrid electric vehicles, and combined the dynamic programming and the minimum principle to propose a predictive shift control strategy. To reduce the fuel consumption of commercial vehicles, Erik and Maria [18] optimized the gear and vehicle speed within the predicted area in front of the vehicle based on the geographic location information provided by the navigation system. As the deterministic dynamic programming algorithm is complex and difficult to apply in real time simulation, the neural network was adopted by Xu et al. [19] to make up for this shortcomings. The optimal control of the predictive shift strategy currently studied is based on the road cycle conditions for passenger vehicle. Whether the transmission control unit (TCU) can meet requirements of calculation speed by the real-time predict control still need to be discussed.

However, the mining vehicle only travels between the mining source and the mining plant, which means it has a single driving route, so its road parameters and vehicle parameters are relatively fixed and easier to collect than for a passenger vehicle. Therefore, with the development of smart mining technology, it is possible to use a global optimization control algorithm to get the best shift strategy based on vehicle speed, throttle opening, vehicle load, and road slope in the whole working cycle to replace the traditional twoparameter shift strategy $[20,21]$.

This paper proposes a modified shift strategy based on the vehicle load and road slope, and uses dynamic programming (DP) to solve the global optimal shift schedule of heavy-duty mining trucks. Modelling of the powertrain system is carried out in Section 2. Economical shift strategy based on the vehicle load and road slope modification and the traditional two-parameter shift strategy is given in Section 3. Optimization of the AT shift strategy based on the DP algorithm is described in Sections 4 and 5 presents a comparison of the optimized results with the traditional two-parameter shift strategy in the typical mining working cycle of heavy-duty mining trucks. Concluding remarks are given in Section 6.

\section{Modeling of Heavy-Duty Mining Trucks Powertrain System}

Figure 1 shows a schematic diagram of the $6+2$ speed AT powertrain system, which is mainly composed of an engine, a torque converter, planetary gear mechanism, main reducer, and wheel.

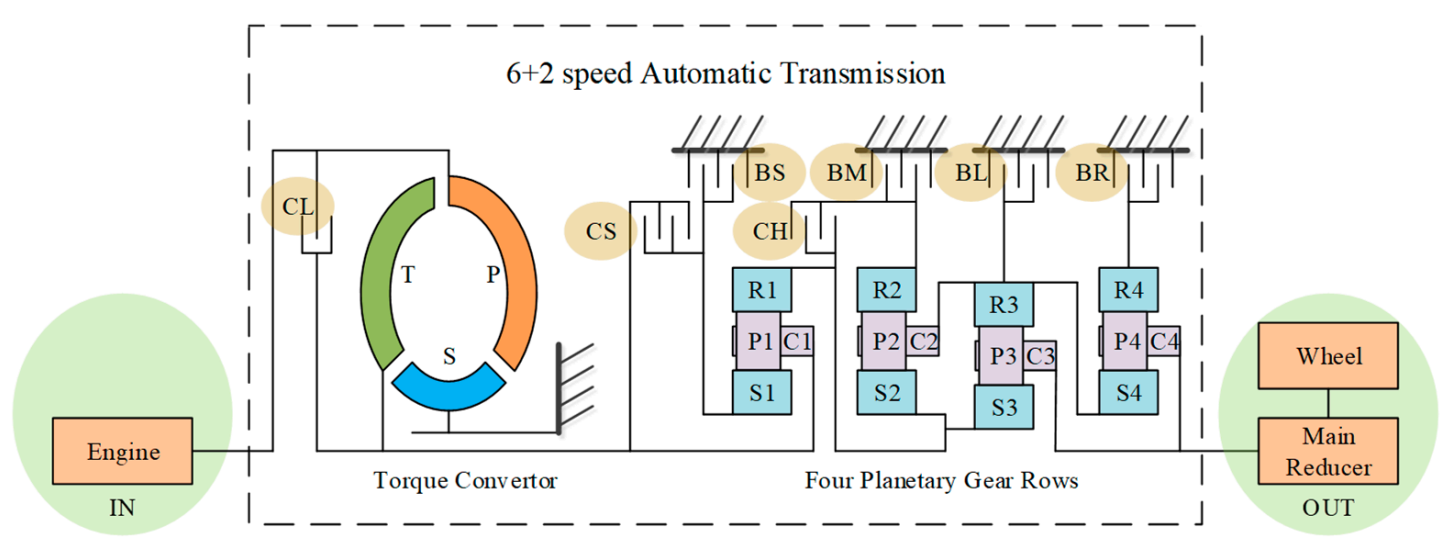

Figure 1. $6+2$ speed AT powertrain system. 


\subsection{Modeling of the Engine}

Related to its rotational speed $\omega_{E}$ and throttle opening $\theta$, the output torque of the diesel engine $T_{E}$ can be described as

$$
T_{E}\left(\omega_{E}, \theta\right)=T_{P}+I_{P} \dot{\omega}_{P},
$$

where $T_{P}, I_{P}$, and $\omega_{P}$ are the pump torque, equivalent inertia, and speed, respectively. Figure 2 shows the engine fuel consumption characteristics map. Through the look-up map, the fuel consumption rate $b_{E}$ can be obtained, based on the engine speed and torque.

$$
b_{E}=b_{E}\left(\omega_{E}, P_{E}\right)=b_{E}\left(\omega_{E}, \omega_{E} \cdot T_{E}\right),
$$

where $P_{E}$ is the engine power.

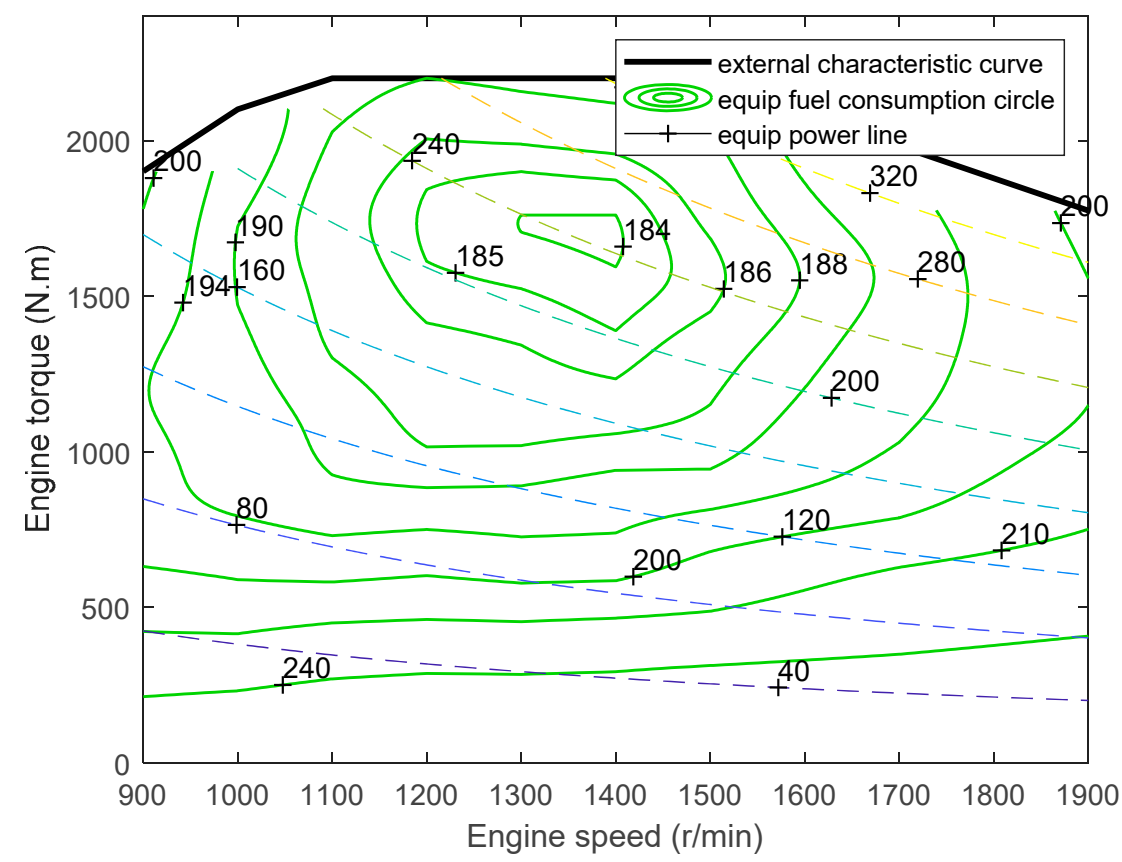

Figure 2. The engine fuel consumption characteristics map of the heavy-duty mining truck.

\subsection{Modeling of the Torque Converter}

Equipped with the lock-up clutch $C L$, the torque converter will enter the working mode to provide a higher output torque in low gears (first and second gears), while it will stop working for better fuel economy in high gears (third to sixth gears). As shown in Figure 3 , the characteristics of the torque converter (including the capacity coefficient $C_{T C}$, torque ratio $K_{T C}$, speed ratio $i_{T C}$, and efficiency $\eta_{T C}$ ) are used to describe their dynamic equation given by

$$
\left\{\begin{array}{c}
T_{P}=C_{T C} \omega_{P}^{2} \\
T_{T}=K_{T C} T_{P} \\
\omega_{T}=i_{T C} \omega_{P} \\
P_{T}=T_{T} \omega_{T}=\eta_{T C} P_{P}=K_{T C} i_{T C} T_{P} \omega_{P}
\end{array},\right.
$$

where $T_{T}, \omega_{T}$, and $P_{T}$ are the turbine torque, speed, and power, respectively, and $P_{P}$ is the pump power. 


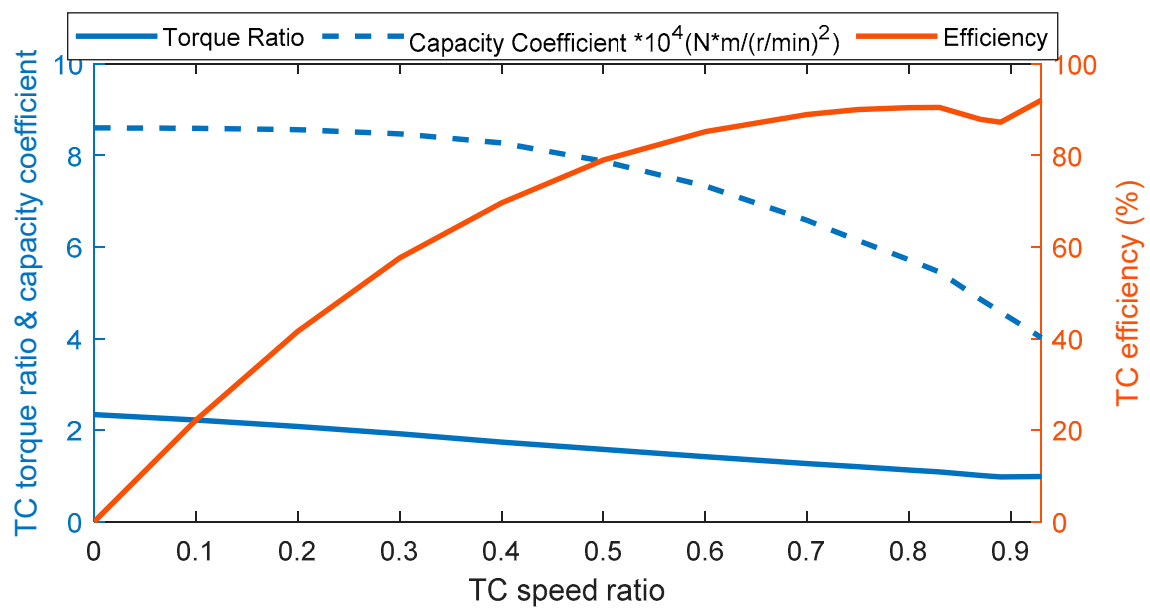

Figure 3. The original characteristics of the torque converter.

\subsection{Modeling of the Planetary Gear Mechanism}

By choosing different clutches or brakes ( $C S, B S, C H, B M, B L$, and $B R$ ) to connect, The planetary gear mechanism realizes the switching of different speed ratios, as shown in Table 1. According to the velocity relationship of a mesh point, the kinematics equations of four planetary rows $(i=1,2,3,4)$ are

$$
\left\{\begin{array}{l}
\omega_{C i} R_{S i}-\omega_{P i} R_{P i}=\omega_{S i} R_{S i} \\
\omega_{C i}\left(R_{S i}+2 R_{P i}\right)+\omega_{P i} R_{P i}=\omega_{R i} R_{R i}
\end{array},\right.
$$

where $S i, R i, C i$, and $P i$ represent the sun gear, ring gear, planet carrier, and planetary gear, respectively, $\omega$ is the angular velocity of the component, and $R$ is the radius. The torque equation of the planetary gear mechanism is

$$
\left\{\begin{array}{l}
T_{S i}: T_{R i}: T_{P i}=1: \gamma_{i}: 1+\gamma_{i} \\
T_{O}=i_{g} \eta_{g} T_{T}
\end{array}\right.
$$

where $T_{S i}, T_{R i}$, and $T_{P i}$ are the torque of the sun gear, ring gear, and planet carrier, respectively, $\gamma_{i}=\frac{R_{R i}}{R_{S i}}$ is the structural parameter of planetary gear row, and $T_{O}, i_{g}$, and $\eta_{g}$ are the output torque, speed ratio, and efficiency of AT, respectively.

Table 1. Combined clutch/brake schedule.

\begin{tabular}{ccccccccc}
\hline Gears & $C S$ & $B S$ & $C H$ & $B M$ & $B L$ & $B R$ & $C L$ & Gear Ratio \\
\hline 1 & $\times$ & & & & $\times$ & & $\times$ & 4.00 \\
2 & & $\times$ & & & $\times$ & & $\times$ & 2.67 \\
3 & $\times$ & & & $\times$ & & & & 2.00 \\
4 & & $\times$ & & $\times$ & & & & 1.33 \\
5 & $\times$ & & $\times$ & & & & & 0.00 \\
6 & & $\times$ & $\times$ & & & $\times$ & & -5.00 \\
R1 & $\times$ & & & & & $\times$ & & -3.33 \\
R2 & & $\times$ & & & & $\times$ \\
\hline
\end{tabular}

\subsection{Modeling of the Main Reducer and Wheels}

Through the main reducer (speed ratio $i_{F D}$ ), the torque output of AT is finally transmitted to the wheels. For modelling convenience, we simplified the longitudinal vehicle model, without considering the vehicle's yaw, pitch, and other motion directions. The output torque of AT is described as

$$
T_{O}=\frac{I_{w} \dot{\omega}_{w}+T_{V}}{i_{F D}}
$$


where $\omega_{w}$ is the wheel speed and $I_{w}$ is the equivalent inertia of wheels.

The vehicle longitudinal resistance torque $T_{V}$ can be described by

$$
T_{V}=r_{w}\left(M g f_{\text {roll }}+\frac{C_{D} S_{V}}{21.15} v_{V}^{2}+M g \sin \alpha+\delta M a_{V}\right)+T_{B}
$$

where $r_{w}$ is the radius of the wheel, $M$ is the vehicle mass, $f_{\text {roll }}$ is the rolling resistance coefficient, $C_{D}$ is the air resistance coefficient, $S_{V}$ is the windward area, $v_{V}$ is the vehicle speed, $\alpha$ is the road slope, $\delta$ is the conversion coefficient of rotating mass, $a_{V}$ is the vehicle acceleration, and $T_{B}$ is the braking torque.

\section{Shift Strategy Modification Based on Vehicle Load and Road Slope}

\subsection{The Traditional Two-Parameter Economical Shift Strategy}

The economical shift strategy means that the shift timing selected by the vehicle should be for the minimum fuel consumption. The fuel consumption per hour of the vehicle is

$$
Q_{t}=\frac{b_{E} \cdot P_{E}}{3600}
$$

When the vehicle is in the non-braking state $\left(T_{B}=0\right)$, the engine output power can be described as

$$
P_{E}=\frac{T_{V} \cdot v_{V}}{\eta_{T}}=\frac{v_{V}}{\eta_{T}}\left(M g f_{\text {roll }}+\frac{C_{D} S_{V}}{21.15} v_{V}^{2}+M g \sin \alpha+\delta M a_{V}\right),
$$

where $\eta_{T}=\eta_{g} \cdot \eta_{T C}$ is the efficiency of the powertrain system. Substituting Equation (9) into Equation (8), we can get

$$
Q_{t}=\frac{b_{E} \cdot v_{V}}{3600 \eta_{T}}\left(M g f_{\text {roll }}+\frac{C_{D} S_{V}}{21.15} v_{V}^{2}+M g \sin \alpha+\delta M a_{V}\right) .
$$

The relationship between vehicle speed and engine speed is

$$
v_{V}=\frac{0.377 \cdot r_{w} \cdot \omega_{E}}{i_{g} i_{F D}} .
$$

From Equations (1), (2), and (11), we can know

$$
b_{E}=b_{E}\left(\theta, v_{V}\right) .
$$

Combine Equations (10) and (12), we can know that the fuel consumption per hour $Q_{t}$ is a function of vehicle speed $v_{V}$, throttle opening $\theta$, vehicle mass $M$, and road slope $\alpha$

$$
Q_{t}=Q_{t}\left(\theta, v_{V}, M, \alpha\right) \text {. }
$$

The relationship between the vehicle fuel consumption $Q$ and the fuel consumption per hour $Q_{t}$ is

$$
Q=\int Q_{t} d t=\int Q_{t} d v_{V} \frac{d t}{d v_{V}}=\frac{1}{a_{V}} \int Q_{t} d v_{V} .
$$

As shown in Figure 4, the vehicle fuel consumption $Q$ is the area enclosed under the fuel consumption per hour curve. The intersection of the two adjacent gears, as shown in Figure 4 point $C$, is the best fuel economy shift point (if there is no intersection, take the minimum position as the best fuel economy shift point at the same vehicle speed, as shown at points $\mathrm{A}$ and $\mathrm{B})$. 


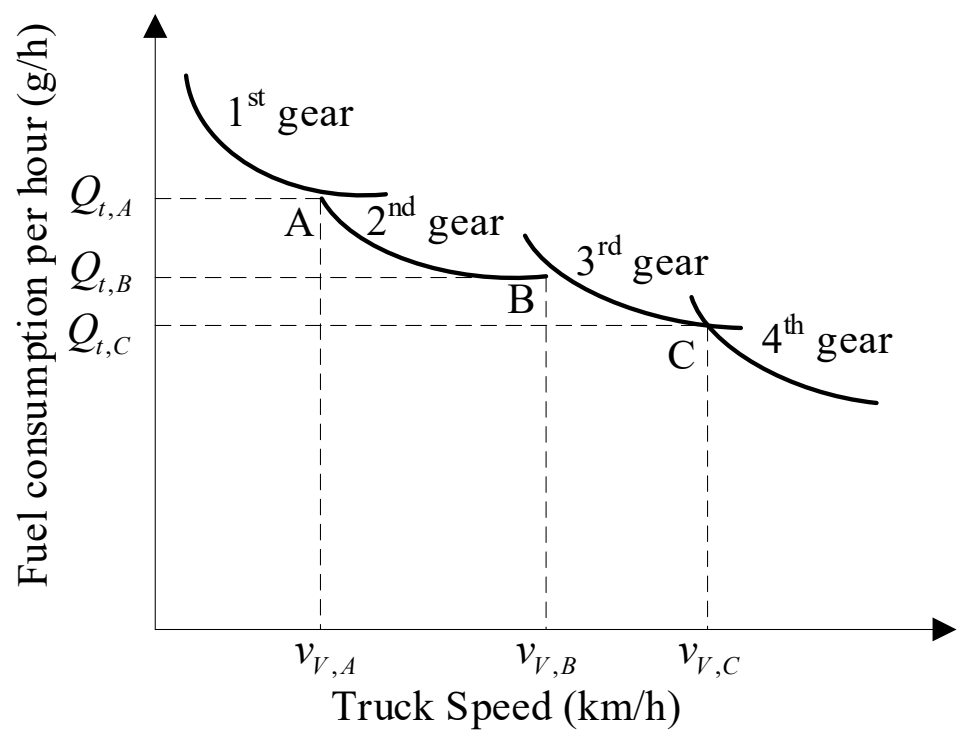

Figure 4. The relationship between fuel consumption per hour and truck speed at different gears.

Integrating the shift points under different throttle openings, the traditional twoparameter economical shift curve of the truck without considering vehicle load and road slope $\left(M=M_{\max }, \alpha=\alpha_{0}\right)$ is obtained, as shown in Figure 5.

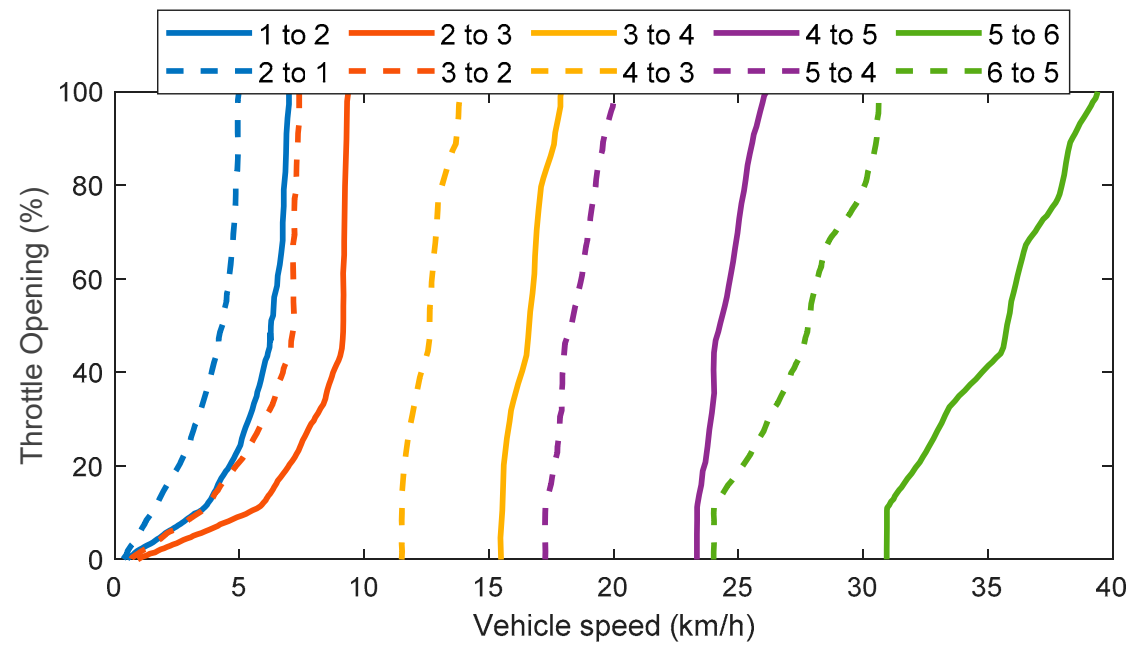

Figure 5. The traditional two-parameter economical shift strategy.

\subsection{Modification of Shift Strategy Based on Vehicle Load}

The self-weight coefficient of heavy-duty mining trucks is much lower than that of ordinary passenger vehicles, and even under $0.7\left(\frac{M_{0}}{M_{\max }-M_{0}} \leq 0.7\right)$. The unloaded mass of the truck studied in this paper is $M_{0}=30,000$, and the full-load mass is $M_{\max }=72,000$. This huge load capacity will have a non-negligible impact on the shift strategy. Assuming that other conditions are constant, according to the aforementioned method, the vehicle speed and throttle opening of the shift point under no-load and full-load conditions can be obtained, respectively. In order to simplify the calculation, this paper chooses the linear interpolation method to obtain the best economy shift point corresponding to any vehicle load.

$$
f(M)=\frac{M-M_{\max }}{M_{0}-M_{\max }} f\left(M_{0}\right)+\frac{M-M_{0}}{M_{\max }-M_{0}} f\left(M_{\max }\right) .
$$


Let $\sigma_{M}=\frac{M-M_{\max }}{M_{0}-M_{\max }}$, then Equation (15) can be transformed into

$$
v_{v, M}=\frac{M-M_{\max }}{M_{0}-M_{\max }} v_{v, 0}+\frac{M-M_{0}}{M_{\max }-M_{0}} v_{v, \max }=\sigma_{M} v_{v, 0}+\left(1-\sigma_{M}\right) v_{v, \max } .
$$

Taking the shift line of the 3-4 upshift as an example, the shift schedule based on vehicle load correction is shown in Figure 6a. From the shift lines corresponding to the three different vehicle loads in the figure, it can be seen that the vehicle load has a great impact on the shift point. At the same throttle opening, the shifting speed increases as the vehicle load increases.

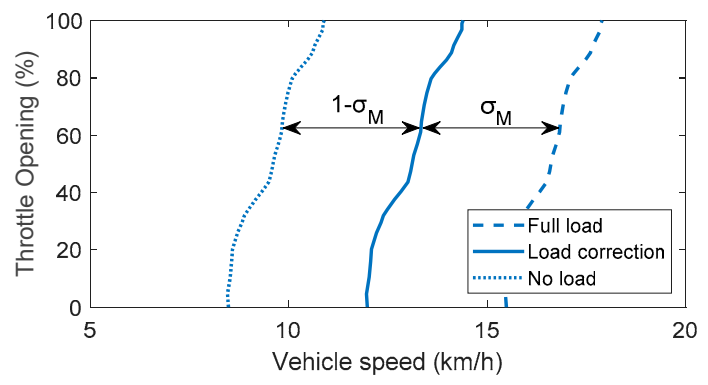

(a)

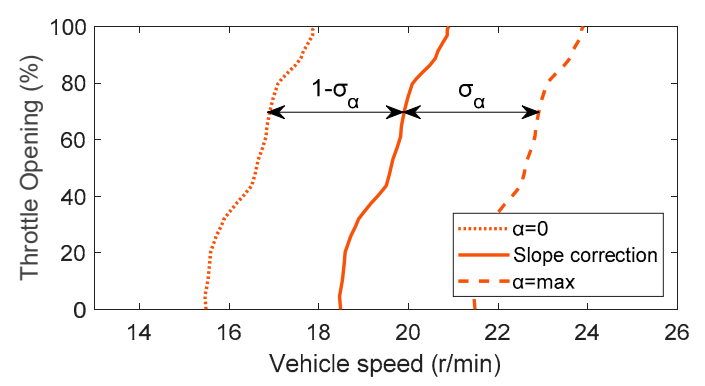

(b)

Figure 6. Modification of shift strategy based on (a) vehicle load and (b) road slope.

\subsection{Modification of Shift Strategy Based on Road Slope}

The slope of the mine road changes frequently, and the maximum road slope is generally greater than the urban road. The maximum slope of the mine road referred to this paper is $\alpha_{\max }=7 \%$. On actual roads, the slope is a continuously changing random variable, so it is impossible to design the shift schedule for every road slope. After using the aforementioned method to obtain the shift schedule of the maximum road slope, the vehicle speed at any other road slope can also be obtained by using the interpolation method.

$$
f(\alpha)=\frac{\alpha-\alpha_{\max }}{\alpha_{0}-\alpha_{\max }} f\left(\alpha_{0}\right)+\frac{\alpha-\alpha_{0}}{\alpha_{\max }-\alpha_{0}} f\left(\alpha_{\max }\right) .
$$

Let $\sigma_{\alpha}=\frac{\alpha-\alpha_{\max }}{\alpha_{0}-\alpha_{\max }}$, then Equation (17) can be transformed into

$$
v_{V, \alpha}=\sigma_{\alpha} v_{V, \alpha 0}+\left(1-\sigma_{\alpha}\right) v_{V, \alpha \max } .
$$

Still taking the 3-4 upshift as an example, the shift strategy based on road slope modification is shown in Figure 6b. It can be seen that the shift point would be delayed under the same throttle opening in climbing working conditions.

\section{Optimizing Shift Strategy Based on DP}

The dynamic programming algorithm is used to solve the optimization problem, by decomposing it into simpler sub-problems, and using the optimal solution of its subproblems to obtain the optimal solution of the overall problem. Compared to the exhaustive attack method, DP not only reduces the amount of calculation, but also obtains many useful intermediate calculation processes [22]. After completing the modification of the AT economical shift strategy based on vehicle load and road slope, the DP algorithm will be used for global optimization.

The gear state $n_{g}(k)$ is used as a state variable, and the shift command $u_{g}(k)$ is used as a control variable. For this $6+2$ speed AT shift command, ' -1 ' means to downshift one gear; 
' 0 ' means to maintain the current gear; and ' 1 ' means to upshift one gear $u_{g}(k)=(-1,0,1)$. As a stepped transmission, it is necessary to discretize the AT gears ratios

$$
n_{g}(k+1)= \begin{cases}1, & \text { if } n_{g}(k)+u_{g}(k) \leq 1 \\ 6, & \text { if } n_{g}(k)+u_{g}(k) \geq 6 \\ n_{g}(k)+u_{g}(k), & \text { other }\end{cases}
$$

Under the known driving conditions with vehicle speed, throttle opening, load, and road slope, the minimum vehicle fuel consumption is established as the optimization objective function, and then the optimal control sequence of the state variables $n_{g}^{*}(k)$ can be solved

$$
n_{g}^{*}(k)=\underset{n_{g}(k)}{\operatorname{argmin}} Q=\sum_{k=0}^{N-1} b_{E}(k) \Delta t .
$$

The optimization objective function of fuel consumption is

$$
J_{k}^{*}\left(n_{g}(k)\right)=\min _{u(k)} Q(k) \Delta t+J_{k}^{*}\left(n_{g}(k+1)\right) .
$$

Under the known actual road conditions, there are some situations where the road slope fluctuates violently. These fluctuations of the road slope may cause sudden changes in throttle opening and braking, while vehicle speed changes with a lag, which will lead the AT into cyclically shift. It is better to avoid or reduce these cyclic shifts because they not only reduce comfort and increase fuel consumption, but also accelerate clutch wear, which seriously affects the service life of the AT.

$$
\eta(k)=\lambda\left|n_{g}(k+1)-n_{g}(k)\right|,
$$

where, $\lambda$ is the penalty coefficients for the number of shifts.

The final objective function of DP optimization is:

$$
J_{k}^{*}\left(n_{g}(k)\right)=\min _{u(k)}\left[Q(k) \Delta t+J_{k}^{*}\left(n_{g}(k+1)\right)+\eta(k)\right] .
$$

Moreover, it is necessary to consider constraints caused by the engine.

$$
\left\{\begin{array}{c}
\omega_{E, \min } \leq \omega_{E}(k) \leq \omega_{E, \max } \\
0 \leq T_{E}(k) \leq T_{E, \max }
\end{array}\right.
$$

The constraint variables in the transmission are

$$
\begin{aligned}
u_{g}(k)=\left\{\begin{array}{l}
\{0,1\}, \quad \text { if } n_{g}(k)=1 \\
\{-1,0\}, \quad \text { if } n_{g}(k)=6 \\
\{-1,0,1\}, \quad \text { other } \\
1 \leq n_{g}(k) \leq 6 \\
\\
\sum_{k-0}^{N-1} u_{g}(k)=0
\end{array} .\right.
\end{aligned}
$$

The known working condition is divided into $\mathrm{N}$ stages, and the sampling step $\Delta t$ is set to one second. Starting from the Nth stage of the last second, the entire condition is calculated from the bottom up to the first stage, so as to obtain the economical optimal solution for each stage of gear $n_{g}(k)$ and shift command $u_{g}(k)$. At a certain time, $k$, the calculation steps based on DP is shown in Figure 7. 


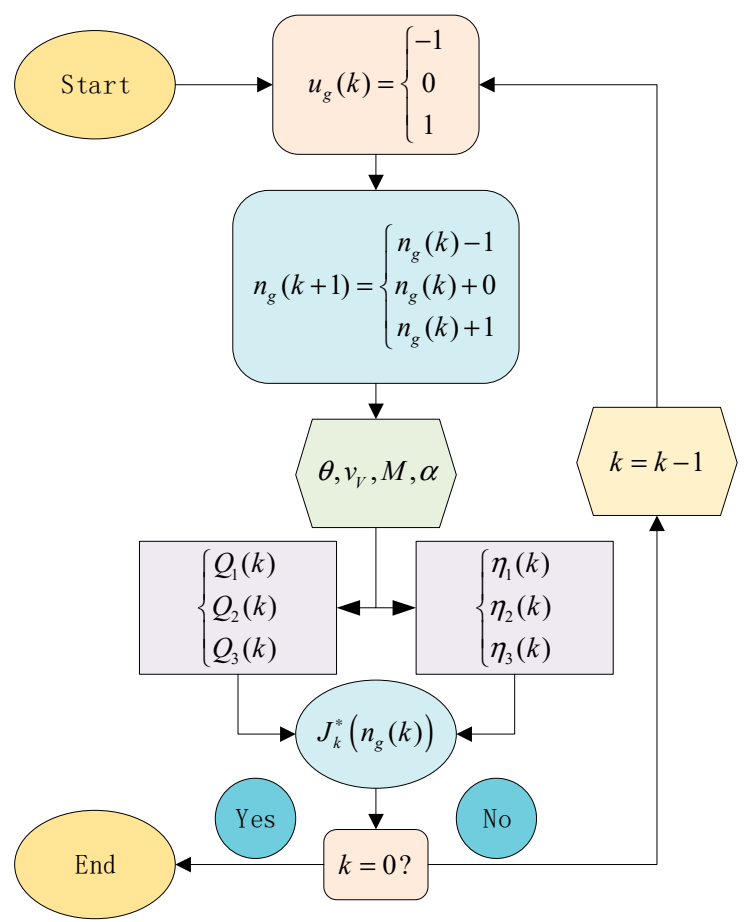

Figure 7. The flow chart of optimizing AT shift strategy based on DP algorithm.

\section{Simulation Results of DP}

According to the actual mine road, the known working condition of the heavy-duty mining truck is shown in Figure 8. The general working state can be divided into four sections: (1) the a-b section is waiting for loading; (2) the $\mathrm{b}-\mathrm{c}$ section is full-load climbing; (3) the c-d section is waiting for unloading; and (4) the final $\mathrm{d}-\mathrm{e}$ section is no-load downhill. On this $10 \mathrm{~km}$ simulation road, the truck speed limit is $45 \mathrm{~km} / \mathrm{h}$ and the maximum slope is $7 \%$. The simulation step is set to $1 \mathrm{~s}$, and the entire simulation time is $2000 \mathrm{~s}$. The vehicle parameters are shown in Table 2.
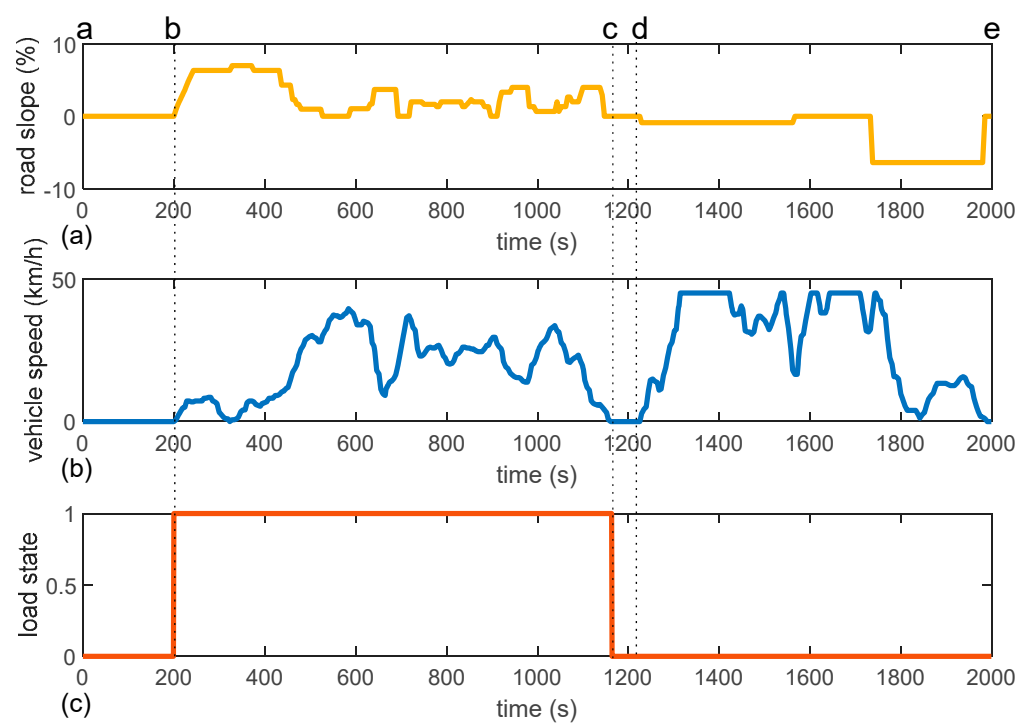

Figure 8. The known working condition information of the heavy-duty mining truck. (a) Road slope, (b) vehicle speed, and (c) load state (1: full-load, 0: no-load). 
Table 2. Simulation parameters.

\begin{tabular}{ccc}
\hline Symbol & Value & Unit \\
\hline$M_{0}$ & 30,000 & $\mathrm{~kg}$ \\
$M_{\max }$ & 72,000 & $\mathrm{~kg}$ \\
$i_{F D}$ & 22.4 & $\mathrm{~m}$ \\
$r_{w}$ & 0.97 & \\
$f_{\text {roll }}$ & 0.03 & \\
$C_{D}$ & 0.8 & $\mathrm{~m}^{3}$ \\
$S_{V}$ & 15 & \\
$\eta_{g}$ & 0.95 & \\
$\alpha_{\max }$ & $10.5 \%$ & \\
\hline
\end{tabular}

Figure 9 shows the simulation results based on the DP algorithm optimization. After the adjustment of the AT, the engine speed and output torque are maintained in a relatively stable and efficient working range, $1200 \mathrm{r} / \mathrm{min} \leq \omega_{E} \leq 1550 \mathrm{r} / \mathrm{min}$ and $1400 \mathrm{~N} \cdot \mathrm{m} \leq T_{E} \leq 1900 \mathrm{~N} \cdot \mathrm{m}$, as shown in Figure 9a,b. According to the difference in vehicle speed, throttle opening, vehicle load, and road slope, the optimized gear is selected properly in Figure 9c. The total number of shifts without shift cycle phenomenon, is 46 times, which is a reduction of $37.0 \%$, compared to the traditional shift strategy, as shown in Table 3. Figure $9 \mathrm{~d}$ shows the growth curve of vehicle fuel consumption, in which the final fuel consumption is $17.6 \mathrm{~kg}$, with a decrease of $8.8 \%$.
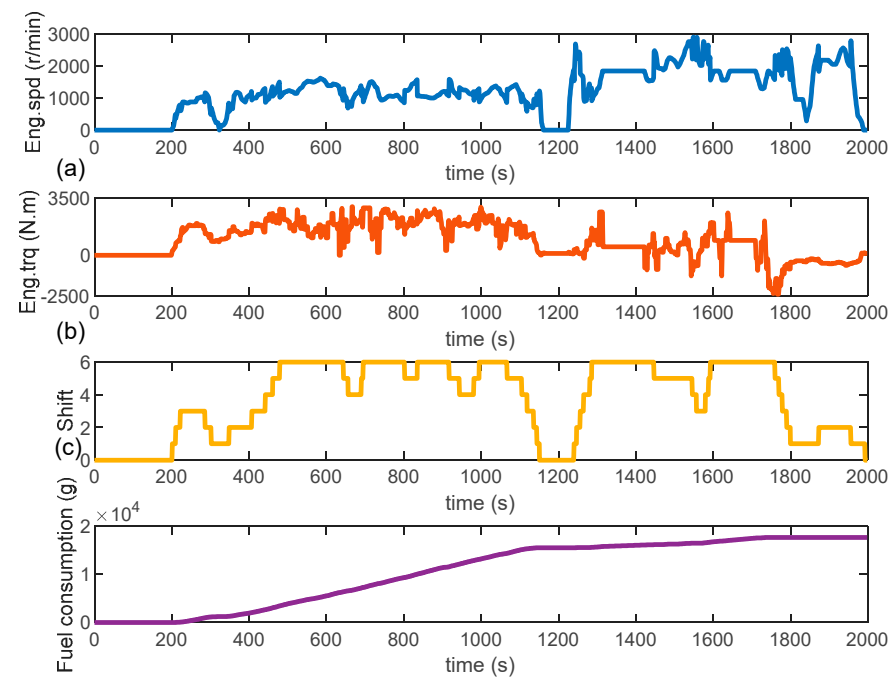

(d)

Figure 9. The simulation results of the optimized shift strategy based on the DP. (a) Engine speed, (b) engine torque, (c) the AT gear selected, and (d) vehicle fuel consumption.

Table 3. Comparison results of shift strategy based on the dynamic programming with the traditional two parameters.

\begin{tabular}{cccccc}
\hline $\begin{array}{c}\text { Shift } \\
\text { Strategy }\end{array}$ & $\lambda$ & $\begin{array}{c}\text { Fuel Con- } \\
\text { sumption }\end{array}$ & $\begin{array}{c}\text { Reduction } \\
\text { Rates }\end{array}$ & $\begin{array}{c}\text { Number of } \\
\text { Shifts }\end{array}$ & $\begin{array}{c}\text { Reduction } \\
\text { Rates }\end{array}$ \\
\hline $\begin{array}{c}\text { Dynamic pro- } \\
\text { gramming }\end{array}$ & $\lambda=0$ & $16.8(\mathrm{~kg})$ & $12.9 \%$ & 67 & $8.2 \%$ \\
\hline $\begin{array}{c}\text { Traditional } \\
\text { two }\end{array}$ & - & $17.6(\mathrm{~kg})$ & $8.8 \%$ & 46 & $37.0 \%$ \\
parameters & & $19.3(\mathrm{~kg})$ & - & 73 & - \\
\hline
\end{tabular}


The engine operating points before and after optimization are compared in Figure 10. It can be seen that the DP optimized engine operating points are more concentrated in the high-efficiency range. Under the same engine output power, the optimized shift schedule can well avoid the inefficient range near $\omega_{E}=1100 \mathrm{r} / \mathrm{min}, T_{E}=1800 \mathrm{~N} \cdot \mathrm{m}$ and $\omega_{E}=1750 \mathrm{r} / \mathrm{min}, T_{E}=1000 \mathrm{~N} \cdot \mathrm{m}$, so as to achieve the best fuel economy.

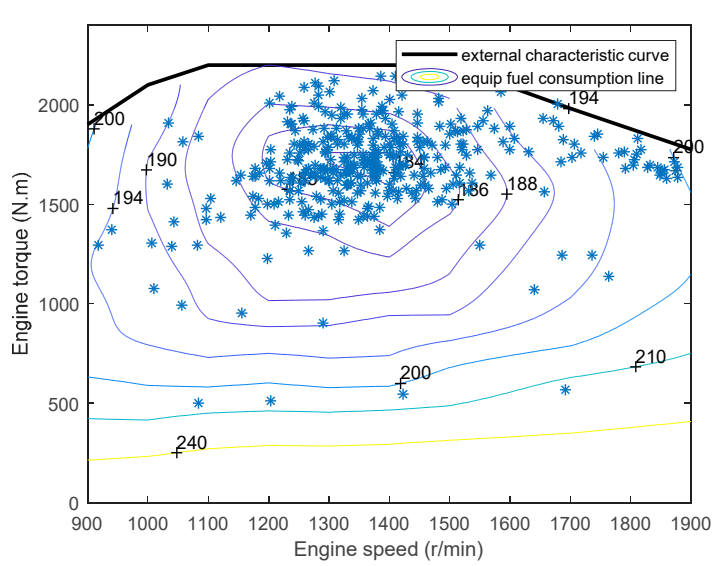

(a)

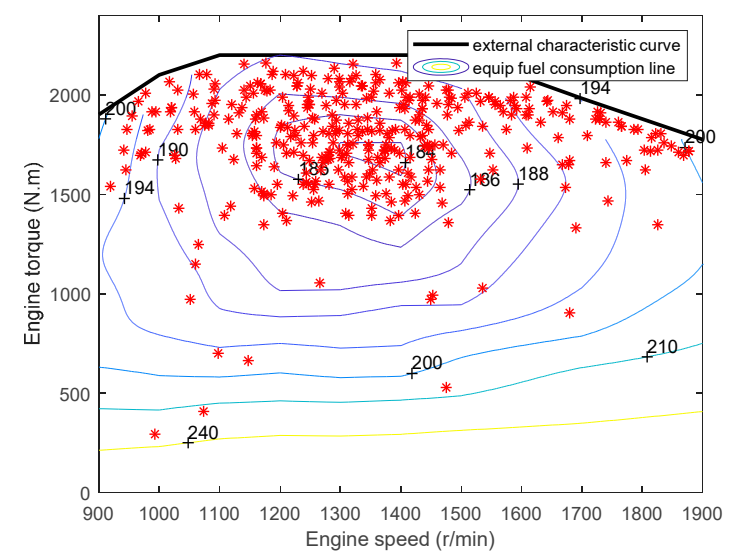

(b)

Figure 10. Comparison of engine operating point. (a) The dynamic programming and (b) the traditional two parameters shift strategy.

\section{Conclusions}

(1) In this paper, the powertrain system model for a heavy-duty mining truck equipped with automatic transmission is built in MATLAB. The traditional economical twoparameter shift strategy is modified according to the vehicle load and road slope. The revised shift strategy shows that the upshift required higher vehicle speed under full load climbing working conditions.

(2) The optimal shift strategy based on a dynamic programming algorithm under known working conditions is proposed. The simulation results show that the proposed shift strategy can effectively reduce the fuel consumption from 19.3 to $17.6 \mathrm{~kg}$ and unnecessary shifts from 73 to 46 times, respectively.

(3) Overall, the DP algorithm to optimize the global shift strategy for heavy-duty mining trucks is feasible and efficient. Hardware-in-the-loop and real vehicle testing will be the key of the future works.

Author Contributions: Conceptualization, H.Z. and X.Z.; methodology, J.Y.; software, H.Z., X.Z., and W.Y.; validation, H.Z. and X.Z.; writing-original draft preparation, H.Z.; writing-review and editing, H.Z., X.Z., J.Y., and W.Y.; supervision, J.Y. and X.Z.; project administration, J.Y.; funding acquisition, J.Y. All authors have read and agreed to the published version of the manuscript.

Funding: This research was funded by the National Natural Science Foundation of China, grant number 51905031; the National Key Research and Development Program of China, grant number 2018YFC0604402; and the Fundamental Research Funds for the Central University of China, grant number FRF-TP-20-036A2.

Institutional Review Board Statement: Not applicable.

Informed Consent Statement: Not applicable.

Data Availability Statement: Not applicable.

Conflicts of Interest: The authors declare no conflict of interest. 


\section{References}

1. Meng, F.; Shi, P.; Karimi, H.R.; Zhang, H. Optimal design of an electro-hydraulic valve for heavy-duty vehicle clutch actuator with certain constraints. Mech. Syst. Signal Pr. 2016, 68-69, 491-503. [CrossRef]

2. Ouyang, T.; Huang, G.; Li, S.; Chen, J.; Chen, N. Dynamic modelling and optimal design of a clutch actuator for heavy-duty automatic transmission considering flow force. Mech. Mach. Theory 2020, 145, 103716. [CrossRef]

3. Zhang, H.; Zhao, X.; Sun, J. Optimal clutch pressure control in shifting process of automatic transmission for heavy-duty mining trucks. Math. Probl. Eng. 2020, 2020, 1-9.

4. Zhang, H.; Zhao, X.; Yang, J.; Zhang, W. Optimizing automatic transmission double-transition shift process based on multiobjective genetic algorithm. Appl. Sci. 2020, 10, 7794. [CrossRef]

5. Zhao, X.; Li, Z. Data-driven predictive control applied to gear shifting for heavy-duty vehicles. Energies 2018, 11, 2139. [CrossRef]

6. Tan, S.; Yang, J.; Zhao, X.; Hai, T.; Zhang, W. Gear ratio optimization of a multi-speed transmission for electric dump truck operating on the structure route. Energies 2018, 11, 1324. [CrossRef]

7. Yang, W.; Liang, J.; Yang, J.; Zhang, N. Optimal control of a novel uninterrupted multi-speed transmission for hybrid electric mining trucks. Proc. Inst. Mech. Eng. Part D J. Automob. Eng. 2018, 233, 3235-3245. [CrossRef]

8. Zhang, G.X.; Li, M.; Wei, X. Research on intelligent shift strategy of automatic transmission. Adv. Mater. Res. 2014, 988, 586-589. [CrossRef]

9. Nejad, A.F.; Chiandussi, G.; Solimine, V.; Serra, A. Study of a synchronizer mechanism through multibody dynamic analysis. Proc. Inst. Mech. Eng. Part D J. Automob. Eng. 2019, 233, 1601-1613. [CrossRef]

10. Li, H.; He, H.; Peng, J.; Li, Z. Three-parameter shift schedule of automatic mechanical transmission for electric bus. Energy Procedia 2018, 145, 504-509. [CrossRef]

11. Lei, Y.; Liu, K.; Zhang, Y.; Fu, Y.; Liu, H.; Lin, G.; Tang, H. Adaptive gearshift strategy based on generalized load recognition for automatic transmission vehicles. Math. Probl. Eng. 2015, 2015, 1-12. [CrossRef]

12. Cao, Q.; Zhou, Z.; Zhang, M. Fuzzy adaptive shift schedule of tractor subjected to random load. Math. Probl. Eng. 2017, 2017, 1-8. [CrossRef]

13. Xia, G.; Gao, J.; Tang, X.; Wang, S.; Sun, B. Control strategy for shift schedule correction based on driving habits for vehicles with automatic transmission. Int. J. Automot. Technol. 2020, 21, 407-418. [CrossRef]

14. Zhang, L.; Zhang, X.; Han, Z.; Chen, J.; Liu, J. A novel multi-parameter coordinated shift control strategy for an automated manual transmission based on fuzzy inference. Proc. Inst. Mech. Eng. Part D J. Automob. Eng. 2017, 231, 684-699. [CrossRef]

15. Lin, C.; Zhao, M.; Pan, H.; Yi, J. Blending gear shift strategy design and comparison study for a battery electric city bus with AMT. Energy 2019, 185, 1-14. [CrossRef]

16. Li, G.; Gorges, D. Fuel-efficient gear shift and power split strategy for parallel HEVs based on heuristic dynamic programming and neural networks. IEEE T. Veh. Technol. 2019, 68, 9519-9528. [CrossRef]

17. Ngo, V.D.; Hofman, T.; Steinbuch, M.; Serrarens, A. Gear shift map design methodology for automotive transmissions. Proc. Inst. Mech. Eng. Part D J. Automob. Eng. 2013, 228, 50-72. [CrossRef]

18. Hellström, E.; Ivarsson, M.; Åslund, J.; Nielsen, L. Look-ahead control for heavy trucks to minimize trip time and fuel consumption. Control Eng. Pract. 2009, 17, 245-254. [CrossRef]

19. Xu, C.; Al-Mamun, A.; Geyer, S.; Fathy, H.K. A Dynamic Programming-Based Real-Time Predictive Optimal Gear Shift Strategy for Conventional Heavy-Duty Vehicles. In Proceedings of the 2018 Annual American Control Conference (ACC), Milwaukee, WI, USA, 27-29 June 2018.

20. Zhao, X.; Zhang, W.; Feng, Y.; Yang, Y. Optimizing gear shifting strategy for off-road vehicle with dynamic programming. Math. Probl. Eng. 2014, 2014, 1-9. [CrossRef]

21. Yang, W.; Yang, J.; Liang, J.; Zhang, N. Implementation of velocity optimisation strategy based on preview road information to trade off transport time and fuel consumption for hybrid mining trucks. IET Intell. Transp. Syst. 2019, 13, 194-200. [CrossRef]

22. Song, R.; Wei, Q.; Li, Q. Adaptive Dynamic Programming: Single and Multiple Controllers; Springer: Singapore, 2018 ; p. 166. 